\title{
Infección de reservorio braquial complicada con absceso subcutáneo
}

Totally implantable venous access ports (TIVAPS) infection with subcutaneous abscess

\section{CASE REPORT}

A 64-year-old woman presented with a 48-hour fever. She was diagnosed in May 2018 with infiltrative left breast carcinoma stage pT1N0, HER2-positive and hormonal receptors, and received treatment with lumpectomy, lymphadenectomy, radiotherapy and adjuvant chemotherapy with trastuzumab. She had finished the treatment 7 days before through a totally implantable venous access port. The patient came to the emergency room complaining of pain, redness and swelling in her front right arm where the brachial port is placed (image 1) accompanied by fever. Suspecting a brachial port infection, the device was removed and empiric antibiotic treatment with vancomycin and cefepime was started. Nevertheless, as the swelling did not improve, a computerized tomography (CT) scan of the upper right limb was ordered showing a subcutaneous abscess (image 2) which was later drained by the General Surgery service. The blood, port and subcutaneous abscess cultures were all positive for methicillin-sensitive Staphylococcus aureus and the antibiotic therapy was de-escalated to cloxacillin during 14 days after the first negative cultures were obtained with a clinical improvement (image 3).

\section{DISCUSSION}

Totally implantable venous access port infections are the main and most dangerous complications of these devices, and they cause an elevated morbi-mortality ${ }^{1}$. The skin microbiome is the most important source of infection, thus, coagulase-negative staphylococci and Staphylococcus aureus, are the most common isolates ${ }^{2}$. Empiric antibiotic therapy must cover gram-positive cocci (including methicillin-resistant Staphylococcus aureus) and gram-negative bacilli (including Pseudomonas aeruginosa) ${ }^{2,3}$. The duration of antibiotic treatment should last 10-14 days after the first negative blood culture is obtained ${ }^{2}$. The removal of the catheter should be performed in case of sepsis, Staphylococcus aureus, Candida spp or Mycobacterium infection, septic embolisms, persistent bacteraemia after 72 hours of treatment with correct antibiotic or local signs of infection ${ }^{1,2}$.

\section{REFERENCES}

1. Lam PW, Volling C, Chan T, et al. Impact of Defaulting to Single-Lumen Peripherally Inserted Central Catheters on Patient Outcomes: An Interrupted Time Series Study. Clin Infect Dis. 2018;67(6):954-957.

2. Mermel LA. Short-term Peripheral Venous Catheter-Related Bloodstream Infections: A Systematic Review. Clin Infect Dis. 2017;65(10):17571762.

3. Dudeck MA, Edwards JR, Allen-Bridson K, et al. National Healthcare Safety Network report, data summary for 2013, Device-associated Module. Am J Infect Control. 2015;43(3):206-221.

Palabras clave: Staphylococcus aureus, reservorio vascular, absceso

Keywords: Staphylococcus aureus, vascular access port, abscess
Figure 1. Right arm where the brachial port is placed

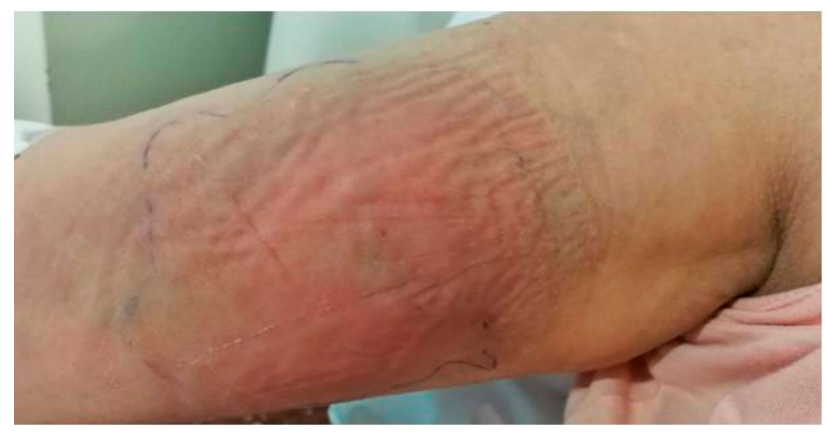

Figure. 2. Computerized tomography scan of the upper right limb: a subcutaneous abscess was observed.

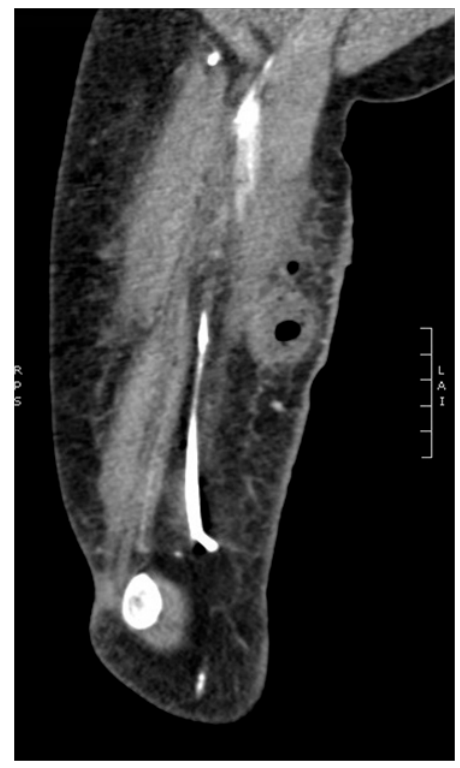

Figure. 3. Right arm after treatment

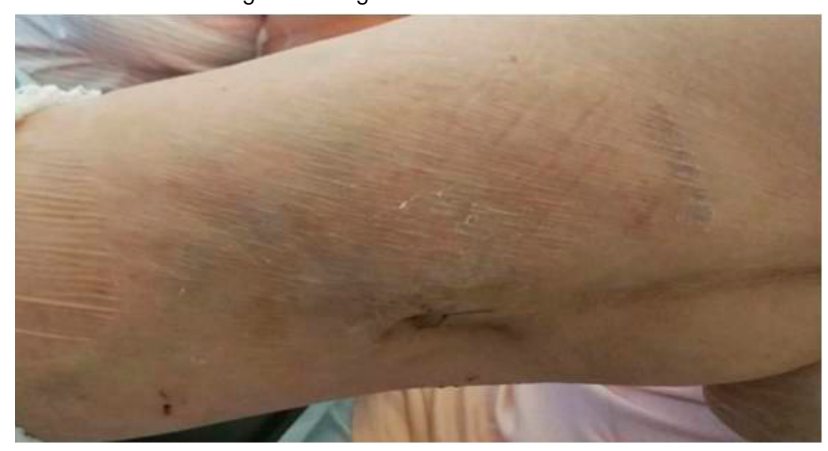

Sonia Morón Losada ${ }^{1}$ Cristina Macía-Rodríguez

'POVISA Hospital, Vigo, España

Correspondencia: cristina.macia.rodriguez@gmail.com

Cómo citar este artículo: Morón Losada S, Macía-Rodríguez C

Infección de reservorio braquial complicada con absceso subcutáneo. Galicia Clin 2021; 82-4: 241

Recibido: 30/7/2020; Aceptado: 30/7/2021 // https://doi.org/10.22546/63/2620 